\title{
CHILD BIRTH EXPERIENCES OF PRIMIPAROUS MOTHERS: A PHENOMENOLOGICAL STUDY
}

\author{
Asma Yunus \\ Assistant Professor, Department of Sociology and Criminology, University of Sargodha \\ $\&$ PhD Scholar Sociology, Institute of Social and Cultural Studies, University of the Punjab \\ asmayounus@gmail.com \\ Khalil Ahmad \\ Professor, Institute of Social and Cultural Studies, University of the Punjab, Lahore, Pakistan \\ khalil.iscs@pu.edu.pk
}

\begin{abstract}
The objective of the study wass to explore the primiparous women's lived experiences of their child birth at an institutional facility. The research phenomenon required an in depth inquiry to get an in depth understanding of primiparous women's perspective. Therefore, a phenomenological research design was selected to study the issue. The researcher has benefitted from the deductive logic (Charmaz, 2006) and used a semi structured interview guide was used as a tool of data collection. Yet it was flexible and was only used to consider the relevant aspect of birthing experience into consideration. For data collection, the potential participants were the primiparous women, who had a live, healthy and vaginal birth with or without epidural, at a health facility, not more than a year ago. Sample size of 10 primiparous women was determined on saturation principle. Participants, from both rural and urban background, were recruited from children OPDs of 4 public and private hospitals in Lahore during Pandemic COVID-19. The concept of birth experience was discussed from social, physical and emotional aspect. The data was recorded, transcribed verbatim and translated in English language. The data was cleaned and researcher developed familiarity by reading and rereading of data. Data analysis was performed following the Van Manon's approach for phenomenological analysis. The cross cutting themes were identified as 1) Meaning and Motives of child birth 2) Physicality during child birth and 3) Continuous Social Support during labor and delivery. The study concludes that every women is unique and so is their birthing experience. Primiparous women feels accomplished on being mother irrespective of the gender of the child if they have a consistent support from their families, spouse and care providers.
\end{abstract}

Keywords: Primiparous women. Birth Experience, Institutional Birth and Vaginal delivery.

\section{INTRODUCTION}

Child birth experience is marked as one of the sought for and vital events for most of the women around the world. The protocols for maternal care during child birth has been changed during last couple of centuries along with the increased emphasis on medicalization. The institutionalized maternal care has been conventionally more focused on obstetric complications while undermining the birthing women's experience (Lundgren \& Berg, 2007). Childbirth, being the most significant event of a women's life, is a profound personal experience especially for first time mothers. First-time mothers mark the event as fearful, anxious, accomplishing, curious and painful in their narratives of birth experiences.( McLeish. et al, 2020) Various dimensions of birth experience are described as positive and negative, having long lasting impacts on mother's self-esteem (McLeish, et al., 2021) self-image, bond with infant, transition to maternal role), future reproductive decisions and subsequent marital quality. (Hildingsson et al., 2020).

The Government of Pakistan has made significant efforts to reduce maternal mortality through a variety of mother-and-child healthcare programs, including the Family Planning and Primary Healthcare Program, the national maternal and child health program, safe motherhood initiatives, and skilled birth attendance with rapid referral for emergency care. Although overall health spending has increased, health spending as a percentage of GDP remains significantly low. Pakistan 
has made some headway toward its goal of lowering maternal death rates over the years (WHO, 2021).

One possible explanation for this failure is that current maternal health initiatives do not recognize in depth accounts of women's childbirth experiences from human rights perspective. Given that it has already been demonstrated that mother's empowerment is critical to improve the delivery experience, a full explanation of the meanings mothers attach to their birthing process is needed. Otherwise, a terrible birth experience at a health facility, from a mother's understanding, may leave them unsatisfied and lead to future care discontinuity. This situation requires a study to document the narrations and perceptions of women's child birth experiences.

\section{REVIEW OF LITERATURE}

This section briefly discusses the relevant literature about various aspects of birthing experience. The importance of birthing experience requires an emphasis to find out the psychosocial elements of birthing experience which are important for, especially first time mothers. Previous literature suggests that even in developed parts of the world, first time mothers seek professional care because of their worry and anxiety before giving birth. (Nilsson et al, 2013). Fear of labor, caesarean section, mother and newborn health, health care professionals' behaviors, and future family life post-partum are all aspects that women are terrified of throughout pregnancy and childbirth (Wigert et al, 2020). Fear may be a result of women being terrified by other people's stories about various complications of birthing process which may cause stress which may negatively influence a woman's daily life, such as a wish for delayed pregnancy and a preference for elective caesarean section (Adalia et al., 2021). Some research findings also emphasize women's specific needs for assistance during labor and delivery, such as being treated as a unique human and having a trustworthy relationship (Downe et al, 2018).

During the delivery phase, women often want to feel safe and participating in decisions that affect them (Tabaghdehi et al, 2020; Wahn et al, 2005). Providing proper support during labor is a difficult task. As a result, assistance from family, spouse and professional care providers (Nstedt, 2005; Price, Noseworthy \& Thornton 2007; Backstrom \& Wahn, 2011) is critical (Lundgren \& Berg, 2007). Good communication and competent behavior can help in building a trustworthy relationship. Primiparous women can be assisted and directed by the care providers on their own conditions in both routine and high-risk situations by giving them a sense of control. (Breg at al. 2008).

Furthermore, professional support of high quality can also help women's feelings and relationships with their infants (Ekstrom \& Nissen, 2006; Price, Noseworthy \& Thornton, 2007). Effective health care related to childbirth should be evidence-based; consequently, more study on women's labor experiences is needed in order to produce the care that women want (Tasuji et al, 2020). Empowerment of a birthing mother has become more popular in the domain of medical Sociology over a couple of decades as a way to strengthen the mother and her family (ICM, 1993). It focuses on empowering women to be more active in maternity and child healthcare (Labonte, 1994; Hermansson \& Martensson, 2011). More understanding about their personal experiences and reflections is required in order to empower primiparous mother. Keeping in view the research gap on woman centered birth experiences of primiparous mothers, the study aims to unfold the social, emotional/cognitive and physical aspects of birthing experience.

\section{MATERIAL AND METHODS \\ Research Design}

Considering the nature of the study, Van Manon's hermeneutic phenomenology was considered as the most appropriate design to get a holistic view of the phenomenon under investigation. (Smith, 2007). The study benefited from deductive logic and anticipatory codes were derived from literature review which unveiled the less explored aspects of the phenomenon. (Charmaz, 2006) This anticipatory code book has been further extended in the process of data collection. This study's data gathering approach relied on women's descriptions of their first-time birthing experiences. Thematic analysis is a systematic way of categorizing ideas, feelings, and actions in a text. The analytical approach seeks to stay close to the text's terms while eliciting contextual meanings. (Manon, 1997). Based on the amount of abstraction, content analysis might be manifest or latent. Manifest content refers to the text itself, while latent content refers to the nuances of meanings attached to the text. (Krippendorff, 
1980). This study has used latent content analysis to find the in-depth meanings primiparous women associate with child birth.

\section{Sample selection and Participants}

The first time mothers who had a live, healthy and vaginal birth with or without epidural, at a health facility, not more than a year ago were considered as the potential research participants. The sample size of the study was based on data saturation principle and sample was recruited through purposive sampling technique. (Silverman, 1987) The mothers who visited children OPDs were requested to volunteer for volunteer participation in the research. First, the primiparous woman were provided information about the study, its objectives, and the rights of the research participants orally and then through consent form was duly signed by the mothers. The researcher followed the ethics of privacy, confidentiality and informed consent. The first-time mothers were given a semi structured interview guide to freely describe various aspects of their birthing experience.

\section{Data Generation and Analysis}

Ten first-time mothers were interviewed to collect data after their post-partum period but no more than a year ago. The written accounts were dense with detail about the birthing experience. Simultaneous data collection and analysis were conducted in order to monitor emerging difficulties and determine when they reached saturation. The text of interview data was transcribed and thematically analyzed (Krippendorff, 1980). The author examined the text of interviews multiple times, reviewed, compared, and validated them. Further the author familiarized herself with the text through frequent readings. The meaning units were recognized as words and sentences pertaining to the research topics. (Silen-Lipponen et al., 2004). Then the data was reduced and coded. The codes were classified into subcategories, which were then classified into categories. Subsequent analysis of the data was conducted by reading across categories, looking for new relationships and significance in the data. Finally, findings were examined and reflected upon in light of the study topics, and an overarching theme developed (Mayan, 2001).

The data shows a cross cutting theme that "If the expectations and reality of child birth experiences are congruent, it will increase the satisfaction with the birthing process among first time mothers". The core categories identified from the data are: 1) Meaning and Motives of child birth 2) Physicality during child birth 3) Continuous Social Support during labor and delivery. Direct quotations are used to present each category and its subcategories in a conversational style. A pseudonym (P1-P10) has been assigned to all 10 research participants.

\section{DATA ANALYSIS AND DISCUSSIONS Meaning and Motives of Child Birth \\ Spiritual value of motherhood}

Religion and spirituality are two major cultural factors that give significance to people's actions, values, and experiences (Ramie, A., Afiyanti, Y., \& Pujasari, H., 2017). Multiple studies from around the world have proven the importance of birth practitioners being aware of women's religious and spiritual needs during pregnancy and birth (Ohaja, Murphy-Lawless and Dunlea, 2019; Sampson 2014; Yesufu, 2016). People regard Allah as the supreme caretaker. Some of the study participants saw their pregnancy as a blessing from Allah Almighty. As a result, they have faith in Him as the primary caregiver, and they carry out their responsibilities as caregivers under His guidance. Mothers used to pray for their babies' gender, beauty and health during the pregnancy.

"It is all Allah's will, if He bless us or not." (P3)

The Participants also mentioned to recite verses of Quran as a pain alleviator during contractions and pain. They also kept on praying for their babies' and their own considering Allah as the supreme power. For safe delivery, the females were sure that Allah has all the supreme powers as one mother said:

You should have faith in both yourself and Allah. Honestly, faith in Allah makes it easier to pull the child forward. I was continuously reciting Kalima while pushing my baby for delivery. Its' all Allah's mercy and blessing that he give me such an adorable baby. (P1) 
"It's not easy, but if you have faith in Allah, Allah will be on your favor, and you'll have a baby with a very less struggle". (P9)

Another participant also added when someone is pregnant or having contractions, she is too close to Allah and He listen to her every prayer. She said that:

"I is a common believe that When someone is pregnant, Allah listen to her every prayer. And when I was in hospital, and had contractions, many of my friends, and cosines call me to pray for them." (P3)

\section{Empowerment and Self Confidence}

This theme examines how women felt empowered by their transition into the role of a mother. The move from "female" to "wife and a mother" has sometimes been perceived as more difficult.

It seemed like the conclusion of an existence and the start of being something new. In reality, I truly bid farewell to the 'never mother'. Now I was a mom and I was feeling proud on me and like stronger than ever. (P4)

Especially the addition of a male child in the family may exalt the status of a woman in her in laws family. Furthermore, sometimes marital conflicts are resolved because of the children as they are the adhesive power of a family in Pakistani society:

"After having a baby boy I feels my position strong in my in-laws and my relationship with my husband has been strengthened" (P7)

A higher level of self-assurance has a favorable impact on delivery. Women who report feeling confident throughout pregnancy and labor feel more in charge, are more educated when making decisions, and view their labor and delivery as less painful and happier (Lowe, 1991) The discovery that a woman's confidence in her capacity to cope with labor pain influences her experience of pain throughout childbirth, for instance, has prompted increasing clinical and science selfconfidence throughout birth (Tasuji, 2020). On the other hand, fear and anxiety are linked to more significant pain during labor and delivery. They require medical pain medication, have struggled for a long time, and may be in danger of an emergency caesarean section (Alehagen, 2001; Johnson and Slade, 2002).

In response to the self-confidence regarding the labor pain and delivery, a respondent expressed:

I was very confident throughout my pregnancy that I have a higher pain threshold. I never experienced myself physically or emotionally weak during pregnancy period.

My family and husband gave me a lot of support to continue my care. (P5)

Women who trust themselves, their bodies, and their abilities to give birth feel safe during pregnancy and the childbearing process, and they characterize their delivery experiences positively (Karlström, Nystedt \& Hildingsson, 2015). According to Namey and Lyerly (2010), personal security is a component of the control concept because it helps women cope with the birth scenario while reducing worry.

One participant shared that her brother's wife suggested her to have a good food before going to hospital and taking labor pains at home until the water bag ruptures. She said:

"You truly expect that the health care specialists can support you, but most of the moment you have to do it yourselves. I bear pain but I was motivated that I will deliver. And out of this burning pain, I was able to deliver my beautiful daughter" (P6)

The literature shows that high self-efficacy expectations and the employment of coping mechanisms during early labor are linked to a positive birthing experience. Women who trust in their abilities to cope with discomfort and have a great mentality about delivery are not terrified to bear children. Those women strive to retain control and utilize all of their energies to achieve a natural vaginal delivery; they also employ coping strategies more and longer, resulting in a better encounter. Furthermore, it is also discovered through literature that high self-efficacy was related to a more favorable experience even in difficult deliveries needing instrumental intervention and medical assistance. The following are some of the participants' replies about self-efficacy: 
I truly didn't anticipate it to be so awful. I believe I am a person who can take a lot of pain but I was not. The suffering was so intense during the maximum phase that I was no longer responsive to it. Nevertheless, after reflecting on the situation just after birth of my child, I believe it is effective. (P7)

\section{Physicality in Child Birth \\ Perception and Meaning of Pain}

Pain during vaginal delivery is not an illness or a disease; it is indeed a natural element in delivering a baby and subsequent generations. Psychological, social, and cultural factors may impact women's pain reactions and the use of pain control measures. In this context, four sub-themes emerge: pain is hard to define, the significance of birthing pain, facing it or escaping it, and pain management strategies. The experience of delivery pain of the participants is discussed here. Pain during delivery is personalized since it is more than just a physical ailment. It adds cognitive, societal, and cultural elements into the point of view (Melzack, 1993). A lady's opinions regarding delivery pain, particularly its utility, influence her choice of pain treatment measures. One key element that determines a woman's pain sensitivity and persistence would be the context of birthing pain (McLeish et al., 2021)

Cramping, stinging, hurting, throbbing, pressing, and piercing are some of the words women use to express their pain sensation. The level of pain varies a lot, but it usually gets worse as labor develops. Even without pain medication, some women suffer only minor discomfort. In the dilatation and pushing phases of labor, the origins and experiences of pain are distinct. Pain is differently perceived by the person in pain and the social group. Some mothers shared people's views about dealing with the pain. One of the respondents shared her MIL's views about dealing with pain:

There is no need for you to cry or shout since it serves no purpose whether you cry or not. You're going to give birth to the child whether you cry or not, so don't cry if you're in pain; you have to give birth to the child. Whatever you ate in pregnancy will be used now. (P7)

One participant shared the rudeness of a nurse and quoted her like this:

Because I believe that if you are terrified of pain, you will work against yourself throughout delivery, attempting to avoid suffering and making it worse rather than allowing it to heal. (P5)

While one mother self-motivated her to deal with the pain and said to her:

I told myself that I must then focus and be calm. Afterwards I succeeded, and it was gone. It was just like hitting a trigger; because you really cannot say it out loud as people would think you are insane. (P1)

\section{Choice of pain relief methods}

Despite the discomforts associated with birthing process, women stated that labor is a natural occurrence. Women belonging to various social context may choice pain relief methods on the basis of their positionality. For some, the procedure was not seen as a source of pain or a sacrifice for the child. They recognized that suffering was an inevitable part of the process. Some women, however, believed that women should not be in such misery. As a result, there were many perspectives on delivery pain, implying that different women may select different strategies to cope with the pain. (Goodman, 2004). Some women especially those who delivered at home or any rural facility were provided with traditional relief methods while in urban hospital, some had informed choice of having epidural although many participants revealed that they were not provided epidural in spite of their continuous request to the care provider.(Nilsson et al., 2013)

A participant from rural background shared:

When I was in labor, I used to like the outdoors. I walked with a helper to relieve pain. I was given massage by Dai (TBA), hot milk with pure ghee to relieve discomfort and expedite the birthing process. I was refrained from taking medicines as it will relieve the pain but the baby will stay in there. So all I wanted for the anguish was to increase and the baby come out safely. (P6)

Some changes in body postures may also relieve the pain. Like kneeling down, breathing via nose or wrapping the arms around waist may relieve the pain. One Participants described:

"I have heard that you breathe via your nose when you're in agony. I was performing when the symptoms started, and it helped to relieve the agony."(P8) 
The most preferred choice at institution facility may be the use of pharmaceutical pain relief methods like epidural. Women belong to urban areas and working women preferred to choose safe methods for pain relief:

Why not, if sophisticated technology exists. It is because it's excruciatingly uncomfortable. It's the most excruciating during labor. Why should a woman suffer so much pain when it can be escaped without compromising the child safety? (P2)

Another women advised others as well:

The epidural worked incredibly well. I would strongly advise other women to try it. I was able to sleep since I was pain-free, which made my labor seem quicker and I wasn't too fatigued to push the baby out. (P3)

\section{Insensitivity of Mother's Embodiment knowledge}

Several participants described how women's own embodied knowledge was ignored in favor of their care provider's interpretation of events:

I felt as though I was being told I was crazy for believing I was in labor and that this excruciating agony was unimportant." Because I was a first-timer, my perspective was rejected and ignored. (P4)

The identification whether the labor process has been started or not is solely build on care provider's clinical assessments while women should be perceived as the experts of their bodies and their judgment about the opening of body should be considered. One lady, for instance, was told she was not in labor because her cervix wasn't dilating as expected by her care provider:

The hospital personnel didn't listen to me and didn't trust me to know what was going on with my body. Dismissed me as an overreacting first-time mother. In fact, it took me little over an hour to dilate from 0 to 6 . While the hospital staff said that I was only experiencing period discomfort linked with early labor and induction. (P7)

Depending on an abdominal palpation, another woman's care provider judged she was not contracting, and hence not in labor:

I was in early labor and the midwife palpated a contraction and said I was not having them. As they continued to ignore me, I eventually went into labor. Despite the fact that my trip was not unpleasant in medical terms, I was quite dissatisfied that it was not accepted on its own merits and that I was entirely neglected as a woman throughout labor. (P9)

Both of these ladies believed they were in labor, and it was upsetting to have their embodied knowledge dismissed. Embodied knowledge was also ignored when women felt compelled to push before their care providers thought it was safe to do so. Women were told to disregard what was going on inside their bodies and to stop pushing:

"I was ordered to stop pushing and instructed what to do even though my body was telling me otherwise. When the baby was definitely on its way, I was advised to stop pushing."(P10)

Clinical evaluations (vaginal exams) were utilized by care professionals to decide if pushing was acceptable. Women were told to ignore their own physiological impulses based on the outcomes of these clinical assessments:

I felt the deepest interest in pushing, but the on-staff nurse persisted on an investigation to assess dilatation; she informed me that if I pulled now, my cervix would expand and I would need an emergency cesarean section. She spent the next hour shouting at me not to push and attempting to get me to have an anesthetic. I was trying my hardest to not push but my body kept taking over. I begged to be given permission to push. (P1)

Women's personal assessments of childbirth phase and foetal position were not recognized or acted on in these accounts, causing distress.

\section{Detachment with the bodies}

The females who had vaginal childbirth without anesthesia were taken aback by the tremendous physicality of giving birth, the enhanced feelings, and sentiments of their own body 'splitting' towards becoming two bodies. (Tabaghdehi et al.,2020). They were able to completely feel the physical elements of child birth since they were not anaesthetized, but they were able to express these experiences in realistic words. Many of these ladies described how their perineum expanded to suit 
the baby's body, causing agonizing discomfort. (Sjögren et al., 2004). At this moment, the line between something within and confined (the child and placenta) and what is out was blurring. The routine of contractions preceding the second stage is disturbed at this period of delivery, and women must come to grips with sensory pleasures and impressions of their bodies and those of the unborn. When the child's head begins to emerge from the female uterus and she experiences it both within and outside her body, these feelings are frequently the most intense. (Stenglin \&.Foureur, 2013).

Women often feel like they have already lost control of life at about this point in childbirth, as the need to push the child out grows overpowering. One participant phrased it this way:

"Essentially, it was out of my hands. I probably wouldn't feel like I could do anything

about it. I was out of this universe" (P3)

Some female's descriptions of the time of delivery and its aftermath revealed that they felt as if their organs were crumbling and that the purity of their physical barriers had been destroyed. They used terms to imply that they felt a threat to their beings' interiors that the stuff of their organisms' interiors may collapse or seep out. One of the participants shared her sensation of leakage and loss of confinement which seemed unmanageable at that time. She described it like this:

I would sense it all gushing out of me. I recall feeling like my insides spilled out when I first came out, along with pretty much everything else. I felt my body 'opening' to the world as its limits were extended and enlarged, and how vulnerable I felt as a result. (P6)

Another participant described the opening of body like this:

"It makes you feel exotic that your body tend to get larger enough that you have to compromise your privacy. Still, they expect that you have to open up even more." (P9)

Most of the primiparous women who gave birth vaginally felt relieved when the baby was finally out of their bodies. They had been through so much pain, discomfort, and effort.

"It felt amazing to pull her entire body from out myself. For who knows how long, her head remained trapped there. The head and body were then extracted, which was fantastic."(P1)

Another narrated it like this:

Then they instructed me to inhale, take deep breaths, exhale" whenever the skull was going to come out. I was sobbing uncontrollably. I was shouting at the top of my lungs. And the head has come out. And it felt fantastic as the remainder of the body emerged. I felt amazingly satisfied and relieved. (P7)

\section{Social Support during Labor and Birth}

At their first births, primiparous mothers wished to be validated and recognized as distinct persons by the medical personnel present. Professionals who respond to the individual woman's requirements for emotional support are more likely to have a pleasant delivery experience, even if the labor is prolonged or there are medical issues during the birth. (Bohren et al 2017). Inadequate support from the midwives could lead to negative birth experience. The first-time mothers could have a negative experience, although well supported by midwives, because of very severe pain or risk of medical complications.

\section{Professional support}

Women's views about the treatment and assistance they got in health institutions ranged from good to negative and unsatisfactory in certain cases. The majority of women were focused on care providers" attitudes, interactions, physical and mentally support, and also how childbirth difficulties were handled. Those who were pleased with their labor experiences defined them in terms of the warm welcome and care they received, the physical and psychological support they received through counselling, and being listened to and having their problems appropriately managed, as some of the mothers narrated:

The doctor was yelling at me to push hard to deliver, I was exhausted and could not do more. An old nurse was proved an angle for me, she put her hands on my stomach and pushed the baby down. I felt motivated and empowered with the support of her hand. I finally pushed and the baby was out (P3) 
While some mothers recounted their delivery memories with optimism and faith in care providers, others used the opportunity to reflect on their despair, pain, and misery. The ladies described noncaring attitudes, inadequate technical care and assistance, as well as quarrelling and physical treatment. One woman who was induced labor shared her experience at labor ward during night as follows:

I had some bearable pains and I was almost comfortable in a comfy bed and cozy environment of labor ward in the first part of the night. As soon as the night grew, I felt that I would not be able to sleep while many women were crying and yelling in pain. The night staff was so rude. Duty doctors were taking tea and coffee and commenting on the women that now they are weeping but happily return their home to come back next year again. I feel so disgusting that they cannot even empathize with laboring women. (P5)

One girl was taken to the maternity ward for birth but was postponed due to unpreparedness on the part of the staff, giving her stress and worry. This was worsened by the fact that she had been left naked, putting her dignity in jeopardy, as she grieved:

Instead of taking me to the maternity ward, they left me half undressed. I felt stressed and ashamed of myself. Why I thought of having a baby. Then I tried to soothe myself but I was vulnerable. There wasn't enough private. Even thinking of it upset me until now. (P9)

Females who had been having a baby for first time required extra details about the childbirth process. The lack of efficient information exchange by care providers was noticed by the females.

\section{Family Support}

As per the mothers" accounts, their childbirth attendants, who were mostly family members (parents, siblings, mothers-in-law, aunties, spouses) and colleagues, valued their participation, intimacy, and physical and psychological support. (Malacrida, C., \& Boulton, T., 2012). Practically, the ladies were accompanied by their birth partners who gave them food and liquids such as tea, encouraged them to walk about before reaching the second phase of labor, and stroked their backs to offer relief throughout pains. According to one study participant:

My sister assisted me in getting tea to sip, stayed about, and at the time when I was having cramps, they could hold me in the shoulder, soothe it, and give me about something like a moment of comfort. (P2)

Another participant who was told that she needed a caesarean delivery remembered:

"When I was having a breakdown at the time, my mother-in-law and sister-in-law were there to support me. They attempted to encourage and soothe me, but it was still a difficult time for me."(P5)

At various periods and in varied ways, the male partners were engaged in intrapartum care of their wives. Despite the fact that their male partners" physical presence was recorded in the hospital, their involvement in actual treatment was not allowed by the hospital's standard operating procedures (SoPs).

\section{CONCLUSIONS}

The findings of the study reveal that primiparous women who delivered vaginally, with or without epidural, had experienced an exhaustive physical sensitivity about the phenomenon. It concludes that women share cultural meanings and motives of child birth. The institution of marriage symbolizes some functional utility for the existence of society. Women described the motives of accomplishment of feminine identity, conformity to social pressure, wish to extend lineage and spiritual reward for being mother are included. The spiritual reward (Sawab) was described as a cause to bear labor pain patiently and without epidural. Further the women had strong memories about the leaking of water, contraction and labor pain, even they identified and exemplified pain with "the cutting of knife, like menstrual cramps if they are multiplied manifold and a breath holding experience". Primiparous women expressed that delivering at an institutional facility was different from the expectations and in the course of labor and delivery, professional and family support had an extensive worth for them to be capable of getting through the birthing process.

\section{LIMITATIONS AND RECOMMENDATIONS}


The study has some limitations as under:

a) It is difficult to generalize the study as the sample is taken from Lahore city and that too through a purposive sampling technique.

b) Furthermore, the study participants are only primiparous women who had a vaginal delivery which excludes a large portion of population relevant to the study topic. Based on the findings of this ground breaking study, a child birth experience questionnaire may be developed and translated in local languages to get a general overview of understanding of women's birthing experience from all over Pakistan

\section{IMPLICATIONS OF RESEARCH}

a) The study provides a holistic view of the factors affecting women's experience of positive or negative child birth and what meanings women associate with the birthing process. These findings may help in identifying issues and strengths of current health care system and will inform policy decisions regarding maternal care.

b) The study findings can also facilitate health care professionals to improve quality of physician-patient interaction and communication to constitute a positive birth experience. It would ultimately contribute to the social and psychological wellbeing of mothers at large.

c) The research is innovative in its nature as there is scarcity of literature on this topic in Pakistani context. Some studies have been conducted by medical professionals however there is a huge gap in Sociological research on the said topic. Although sufficient theoretical knowledge has been developed in various parts of the world yet there is need for context specific theories to comprehend the micro dynamics of the phenomenon. The empirical data and Inductive theory generated as the result of this study can fulfill this felt need in field of sociology of reproductive health.

\section{REFERENCES}

Adalia, E. G., Hernández-Luengo, M., Bartolomé-Gutiérrez, R., Rodríguez-Martín, B., JiménezLópez, E., \& Martínez-Andrés, M. (2021). Expectations and Experiences of Women in Pregnancy, Childbirth, and Infant Feeding: A Qualitative Research Protocol. International Journal of Qualitative Methods. https://doi.org/10.1177/16094069211011901

Backstr \& Hertfelt Wahn. (2011). Support during labor: first-time fathers' descriptions of requested and received support during the birth of their child. Midwifery, vol. 27, no. 1, pp. 67-73

Berg, Bondas, \& Brinchmann et al. (2008) Evidence based care and childbearing a critical approach. International Journal of Qualitative Studies on Health and Well-Being, vol. 1, no. 9, pp. $1-9$.

Bohren et al. (2017). A continuous support for women during childbirth, Cochrane Database of systematic review, issue 7. DOI: 10.1002/14651858.CD003766.pub6

Charmaz, K. (2006). Constructing grounded theory: A practical guide through qualitative analysis. London: Sage Publications.

Downe, S., Finlayson, K., Oladapo, O., Bonet, M., \& Gülmezoglu, A. M. (2018, April 17). What Matters To Women During Childbirth: A Systematic Qualitative Review. https://journals.plos.org/plosone/article?id=10.1371/journal.pone.0194906.

Ekstrom \& Nissen,(2006) . A mother's feelings for her infant " are strengthened by excellent breastfeeding counseling and continuity of care. Pediatrics, vol. 118, no. 2, pp. e309-e314

Goodman, Mackey \& Tavakoli,(2004). Factors related to childbirth satisfaction. Journal of Advanced Nursing, vol. 46, no. 2, pp. 212-219

Hermansson \& Martensson. (2011). Empowerment in the midwifery context-a concept analysis. Midwifery, vol. 27, no. 6, pp. 811-816.

Hildingsson, I., Karlström, A, \& Larsson, B. (2020) Childbirth experience in women participating in a continuity of midwifery care project. Women and Birth. https://www.tandfonline.com/doi/full/10.1080/0167482X.2019.1634047.

https://doi.org/10.1016/j.wombi.2020.10.012.

ICM, International Code of Ethics, ICM,(1993) London, UK 
Krippendorff. (1980). Content Analysis: An Introduction to Its Methodology, Sage, London, UK

Labonte (1994). Health promotion and empowerment: reflections on professional practice. Health Education Quarterly, vol. 21, no. 2, pp. 253-268.

Lundgren \& Berg. (2007). Central concepts in the midwife-woman relationship, Scandinavian Journal of Caring Sciences, vol. 21, no. 2, pp. 220-228.

Manen, V, M. (1997). Researching the lived experience: Human science for an action sensitive pedagogy, second ed. Althouse Press, Ontario

Mayan (2001). An Introduction to Qualitative Methods: A Training Module for Students and professionals, University of Alberta, University Extension Centre, International Institute for Qualitative Methodology, Alberta, Canada.

McLeish J. ,Harvey M. , Redshaw M. \& Alderdice, F. (2021). A qualitative study of first time mothers' experiences of postnatal social support from health professionals in England. Women and Birth, Volume 34, Issue 5,(e451-e460).

McLeish, J., Harvey, M., Redshaw, M., Henderson, J., Malouf, R., \& Alderdice, F. (2020). FirstTime Mothers' Expectations and Experiences of Postnatal Care in England. Qualitative Health Research, 30(12), 1876-1887. https://doi.org/10.1177/1049732320944141

Melender (2002). Experiences of fears associated with pregnancy and childbirth: a study of 329 pregnant women. Birth, vol. 29, no. 2, pp. 101-111.

Nilsson, L., Thorsell, T., Wahn, E. H., Ekström, A., \& H. (2013). Factors Influencing Positive Birth Experiences Of First-Time Mothers. Nursing Research and Practice. Hindawi publishers https://doi.org/10.1155/2013/349124

Ohaja, M., Murphy-Lawless, J., \& Dunlea, M. (2019). Religion and Spirituality in Pregnancy and Birth: The Views of Birth Practitioners in Southeast Nigeria. Religions, 10(2), 82. https://doi.org/10.3390/rel10020082

Price, Noseworthy, \&Thornton. (2007) Women's experience with social presence during childbirth. MCN:The American Journal of Maternal/Child Nursing, vol. 32, no. 3, pp. 184-191.

Ramie, A., Afiyanti, Y., \& Pujasari, H. (2017). Self-control and self-efficacy increase mother's birth labor satisfaction. Jurnal NERS, 9(1), 97. https://doi.org/10.20473/jn.v9i1.3234

Silen-Lipponen, M., Tossavainen, K., Turenen, H., Smith, A., (2004) Learning about teamwork in operating room clinical placement. British Journal of Nursing 13 (5), 244-254.

Silverman, H., (1987). Inscriptions: Between Phenomenology and Structuralism. Routledge Kegan Paul, New York.

Sjögren, B., Edman, G., Widström, A. M., Mathiesen, A. S., \& Uvnäs-Moberg, K. (2004). Maternal foetal attachment and personality during first pregnancy. Journal of reproductive and infant psychology, 22(2), 57-69.

Smith, J. A. (2011). Evaluating the contribution of interpretative phenomenological analysis. Health Psychology Review, 5(1), 9-27. https://doi.org/10.1080/17437199.2010.510659

Stenglin \&.Foureur (2013). Designing out the fear cascade to increase the likelihood of normal birth. Midwifery, 29 (8) pp. 819-825

Tabaghdehi, H., M., Keramat, A., Kolahdozan, S., Shahhosseini, Z., Moosazadeh, M., \& Motaghi, Z. (2020). Positive childbirth experience: A qualitative study. Nursing Open, 7(4), 12331238. https://doi.org/10.1002/nop2.499

Tabaghdehi, M. H., Keramat, A., Kolahdozan, S., Shahhosseini, Z., Moosazadeh, M., \& Motaghi, Z. (2020, April 14). Positive Childbirth Experience: A Qualitative Study. Nursing Open Wiley Online Library. Wiley Online Library. https://onlinelibrary.wiley.com/doi/full/10.1002/nop2.499.

Tasuji T, Reese E, van Mulukom V, Whitehouse H (2020) Band of mothers: Childbirth as a female $\begin{array}{llll}\text { bonding } & \text { experience. } & \text { PLoS } & \text { ONE }\end{array}$ https://doi.org/10.1371/journal.pone.0240175

Wahn, Nissen, \& Ahlberg. (2005). Becoming and being a teenage mother: how teenage girls in south western Sweden view their situation. Health Care for Women International, vol. 26, no. 7, pp. 591-603.

WHO. (2021). EMRO | Pakistan | Countries. (n.d.). World Health Organization - Regional Office for the Eastern Mediterranean. http://www.emro.who.int/countries/pak/index.html. 
Wigert, H., Nilsson, C., Dencker, A., Begley, C., Jangsten, E., Sparud-Lundin, C., Mollberg, M., \& Patel, H. (2020). Women's experiences of fear of childbirth: A Meta synthesis of qualitative studies. International journal of qualitative studies on health and wellbeing, 15(1), 1704484. https://doi.org/10.1080/17482631.2019.1704484 